\title{
Laparoscopic-assisted Appendectomy in Children with Uncomplicated Appendicitis
}

\author{
Saeed Al Hindi, ${ }^{1}$ Husain Al Aradi, ${ }^{2}$ Mohamed Mubarak, ${ }^{2}$ Noor AlHashimi ${ }^{3}$ \\ ${ }^{1}$ Department of Pediatric Surgery, Salmaniya Medical Complex, PO Box 12, Manama, Kingdom of \\ Bahrain \\ ${ }^{2}$ Department of Urology, Salmaniya Medical Complex, PO Box 12, Manama, Kingdom of Bahrain \\ ${ }^{3}$ Department of Pediatrics, Salmaniya Medical Complex, PO Box 12, Manama, Kingdom of Bahrain
}

Correspondence to: Dr. Mohamed Mubarak; email: mohdkej@yahoo.com

Received: 07 December 2019; Revised: 01 June 2020; Accepted: 05 June 2020; Available online: 22 June 2020

\begin{abstract}
Background: Acute appendicitis is one of the common surgical emergencies in the pediatric population. In 1990, laparoscopic-assisted appendectomy was used in children for the first time. In this study, we present our initial experience with laparoscopic-assisted appendectomy in children, using two trocar sites, and assess it for safety and outcome. Methods: 76 cases with acute appendicitis underwent laparoscopic-assisted appendectomy at Salmaniya Medical Complex (SMC), Kingdom of Bahrain, between January 2012 and December 2015. These cases were reviewed prospectively. Results: 76 patients between 5 and 12 years underwent laparoscopic-assisted appendectomy at SMC. Operative time ranged from 25 to $45 \mathrm{~min}$ (mean $33.93 \mathrm{~min}$ ). Postoperative hospitalization ranged from 2 to 5 days (mean 2.88 days). One patient developed wound infection which subsequently subsided with conservative treatment. One case was converted to open appendectomy, but without any intraoperative
\end{abstract}

complications. All patients were followed up for 2 weeks, 1 month, and 3 months postoperatively. Conclusion: Laparoscopic-assisted appendectomy in children is a safe alternative to the open technique. The operative time in this technique and the length of hospitalization are both less and shorter than the open counterpart. No major intra-operative or postoperative complications were documented. Recovery was excellent.

Keywords: Appendicitis, Laparoscopic-assisted appendectomy, Open appendectomy

Ann Afr Surg. 2021; 18(1):34-38

DOI: http://dx.doi.org/10.4314/aas.v18i1.7

Conflicts of Interest: None

Funding: None

(C) 2021 Author. This work is licensed under the Creative Commons Attribution 4.0 International License.

\section{Introduction}

Acute appendicitis is one of the common surgical emergencies in the pediatric population (1). It is primarily a clinical diagnosis, with most patients presenting with the classical history of periumbilical pain which intensifies and migrates to the right iliac fossa (RIF) in the first 24 hours. Associated symptoms such as loss of appetite, nausea, vomiting and changes in bowel habits are often present. Clinically, patients are

commonly febrile, and abdominal examination reveals localized tenderness and rigidity in the RIF, with associated rebound tenderness.

The first diagnosis of appendicitis was made by Robert Lawson in 1880 (2). In 1893, Charles McBurney described the muscle splitting operation for appendectomy (2). In 1980, German gynecologist Kurt Semm performed the first laparoscopic appendectomy 
$(3,4)$. The management of acute appendicitis ranges from non-operative treatment in early non-complicated appendicitis (5) to the gold standard appendectomy with low morbidity worldwide (6-11). In children, morbidity ranges from $2.7 \%$ in non-complicated appendicitis to $16 \%$ in perforated appendicitis (12-15). In 1990 laparoscopic-assisted appendectomy was used in children for the first time (16-18).

The laparoscopic-assisted approach is a technique designed to incorporate the advantages of the complete laparoscopic technique and the open technique. It involves insufflation of the abdomen through an infraumbilical port and the use of 2 trocars instead of the usual 3-trocar technique of traditional laparoscopic appendectomy. In a study by Nicholson and Tiruchelvam, a comparison of the traditional laparoscopic method and the transumbilical laparoscopic-assisted appendectomy (TULAA) demonstrated how TULAA reduces the cost of the laparoscopic technique by USD 400 by reducing mean intraoperative time by 18.6 minutes, the use of surgical supplies, and postoperative hospital stay (1.8 days vs 2.6 days). Such improvements in surgical outcome make TULAA a feasible option in the management of appendectomy (19).

The aim of this study is to present the management and outcome of non-complicated acute appendicitis using the 2-trocar laparoscopic-assisted appendectomy.

\section{Methods}

Seventy-six cases patients presenting at Salmaniya Medical Complex with the clinical diagnosis of acute appendicitis between January 2012 and December 2015 underwent laparoscopic-assisted appendectomy. In our institution, acute appendicitis is a clinical diagnosis. However, laboratory and imaging adjuncts, such as ultrasonography and computed tomography, are used to rule out other differentials when clinical assessment is equivocal. All patients in this study were diagnosed based on clinical features.

In a cohort study, these cases were reviewed prospectively. Patient ages ranged from 5 to 12 years (mean 9.35 years). Complicated cases of acute appendicitis like generalized peritonitis, appendicular mass and appendicular abscess were excluded.

\section{The technique}

Once the diagnosis of acute appendicitis was made all patients were kept on maintenance intravenous fluid and antibiotics. Consent was taken for laparoscopic appendectomy with or without conversion when required.

As for the procedure, the technique described is adapted for our institution. Patients were kept in supine position and under general anesthesia. Foleys catheter and nasogastric tube were inserted. Patients were scrubbed with betadine, with special care given to the umbilical area. A $1.5-\mathrm{cm}$ skin incision was made in the lower edge of the umbilicus and a 5-mm trocar was introduced by open Hasson technique to avoid injury to intraabdominal viscera. Insufflation of $\mathrm{CO}_{2}$ was maintained between 10 and $11 \mathrm{mmHg}$, with a low flow rate of 1.5 $\mathrm{L} / \mathrm{min}$ to reduce postoperative pain (Figure 1).

A 30-degree camera was inserted to visualize the appendix and the intraperitoneal cavity, another 5-mm trocar was inserted in the left lower quadrant using the skin crease for cosmetic reason, then the scope was shifted to the left lower quadrant port and the appendix delivered from the umbilical incision by non-traumatic forceps (Figures 2 and 3).

After deflation of the pneumoperitoneum, appendectomy was performed in a manner similar to the open technique, where the mesoappendix is dissected and the vessels are ligated. The appendiceal stump is then ligated and the appendix is removed.

The umbilicus is not protected with any barrier from the diseased appendix (Figure 2), to facilitate dissection of the mesoappendix and to complete the extracorporeal appendectomy with ease.

At the end of the procedure, all patients had local infiltration with Marcaine (Bupivacaine hydrochloride) and were given Diclofenac suppositories. Subsequently, 

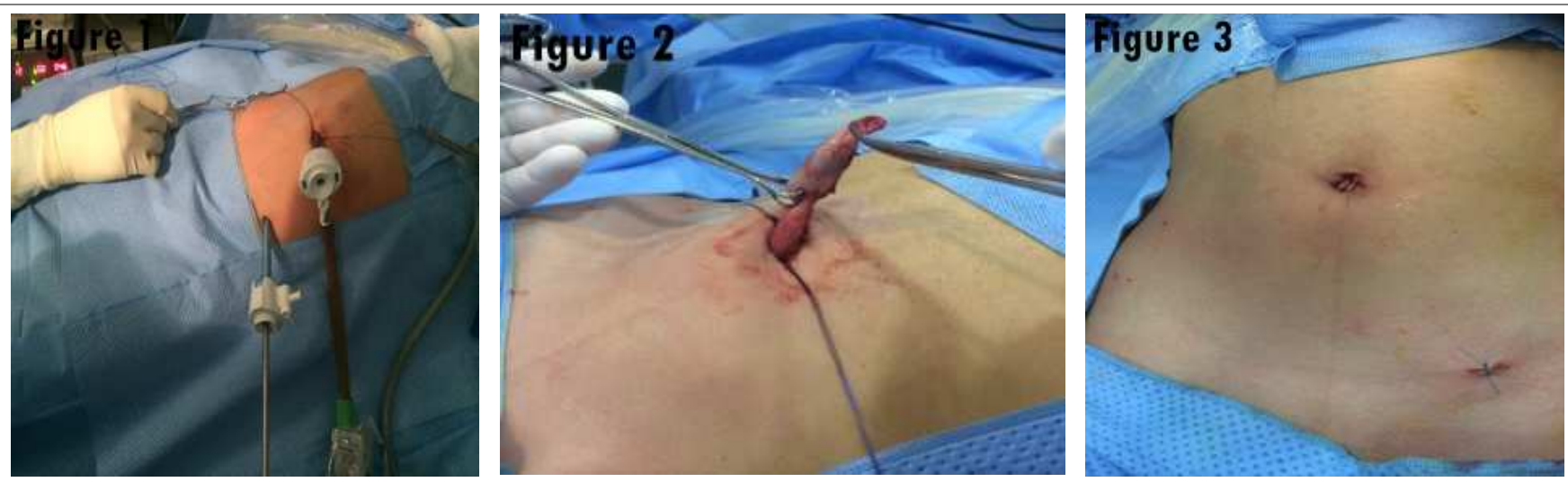

Figure 1: Port insertion and insufflation of $\mathrm{CO} 2$; Figure 2 and 3: Delivery of the appendix via the umbilicus (2) and after closure of access sites.

regular intravenous paracetamol was prescribed for the first postoperative day, and as needed for the rest of the hospital stay. In all cases, postoperative pain was mild, responsive to paracetamol, and did not require any opioid analgesia.

\section{Results}

From 2012 to 2015, 76 patients had laparoscopicassisted appendectomy, 45 were male (59.2\%) while 31 were female $(40.8 \%)$. Patient ages ranged from 5 years to 12 years with a mean age of 9.35 years. The main presenting symptom was abdominal pain in 66 patients while 10 patients presented with loose motion. All cases had associated fever and vomiting. The patients' white blood cell count on presentation ranged from 9 to $14 \times$ $910 / \mathrm{L}$ with a mean of $10.43 \times 910 / \mathrm{L}$.

The duration of the procedure ranged from $25 \mathrm{~min}$ to 45 min. The average time was $33.93 \mathrm{~min}$. Postoperative hospitalization ranged from 2 days to 5 days, with an average stay of 2.88 days.

Postoperative complications include a single case of superficial wound infection at the umbilical incision, which was treated conservatively with local wound care. Another case was documented to have postoperative fever, as a consequence of atelectasis. The 2-trocar technique was successful in all patients, as we did not require the insertion of a third trocar. Only one case required conversion to open appendectomy due to severe intra-abdominal adhesions. There were no cases of mortality.
All patients were followed-up for 2 weeks, 1 month, and 3 months postoperatively, with excellent outcomes. The focus of the follow-up period was to monitor for possible complications, mainly surgical site infection, and to address patient concerns.

\section{Discussion}

The gold standard for the treatment of acute appendicitis was open appendectomy for more than 100 years (5). German gynecologist Kurt Semm performed the first laparoscopic appendectomy in $1980(3,4)$, and since then the trend towards minimally invasive procedures increased exponentially as its benefits include reduced postoperative pain and postoperative hospitalization, and earlier recovery and return to normal life. In 1991, Valla et al. described the use of TULAA in children (20). Our findings in operating time, hospitalization, cost and return to normal activity agree with what was reported by Valla et al. and other studies (20-25).

Although, open appendectomy remains the most common modality to treat appendicitis, laparoscopicassisted appendectomy stands as a good and technically feasible alternative. We found the benefits, such as better visualization of the appendix and the ability to explore and possibly clean the abdominal cavity without the use of any sharp instrument, to be of vital importance, especially in emergency cases. Moreover, such an approach limited any unnecessary injury to peritoneal organs. Another benefit of this technique is that it allows to perform extracorporeal appendectomy 
such as in the open technique with less time and cost $(20,21)$. Furthermore, laparoscopic-assisted appendectomy is much easier to learn than the complete laparoscopic appendectomy. It can be learned at resident levels, and simultaneously provide good exposure and knowledge of the basics of laparoscopic surgery, and therefore enfranchising skills of laparoscopy. However, as reported by Valla et al., the major disadvantage associated with it are the extra expenses required to purchase and maintain instruments and back up equipment (20-25). Despite this, and as reported by Visnjic, the cost of the TULAA method remains 7.8-fold less than that of conventional laparoscopic appendectomy (26) To further decrease surgical expense, Fazili et al. relied on the use of locally modified endoloop and reusable trocars in their study (21). In this study, we used two 5-mm trocars instead of the usual 3trocar approach, which is used in complete laparoscopic appendectomy. The need for less incisions and trocars reduced costs and provided better cosmetic results. It also helped in reducing the operative time of the procedure combined with the ease and safety of extracorporeal appendectomy.

To further support our findings, a retrospective study of 83 patients by Nicholson and Tiruchelvam (19) compared the following different techniques for an appendectomy: laparoscopic-assisted appendectomy, intracorporeal laparoscopic appendectomy, and open appendectomy, with a focus on the following variables: "operative time, surgical expense, and postoperative hospital stay'. It concluded that laparoscopic-assisted appendectomy is a cost effective $(<67 \%$ of the cost of the complete laparoscopic method) and efficient technique, incorporating the advantages of the open and conventional laparoscopic method. Furthermore, an additional advantage of the laparoscopic technique lies in its use as a diagnostic tool. Acute appendicitis is primarily a clinical diagnosis, and so the use of laboratory tests and imaging modalities add to the cost burden. However, with the laparoscopic method, surgeons can simultaneously offer patients a definitive diagnosis and treatment (19). Similar findings regarding the mentioned parameters were also reported by other studies. Kagawa et al. proposed that operative results, mainly conversion rates and operative time, depend on the severity of the inflamed appendix at laparoscopic identification (22). The appendices were classified as either simple (no perforation or abscess) or ruptured (with perforation or abscess). The mean operative time in children was $53.7 \mathrm{~min}$, with a shorter mean operative time in simple cases than in ruptured cases (46.2 min vs $86.7 \mathrm{~min}$ ). Conversion rates to either conventional laparoscopic appendectomy or open appendectomy, simple cases had a conversion rate of $10.9 \%$ compared with $86.7 \%$ of rupture cases. The overall conversion rate in children was $17.9 \%$ and the reasons for conversion included appendix volvulus, appendix immobility and an inflammatory mass (22).

Similarly, conversion rates were higher in other studies than in ours. In a study by Antonacci et al., 6\% of cases required conversion to the standard laparoscopic method, and $9 \%$ of cases required the use of an additional trocar to complete the laparoscopic-assisted operation (27). The authors stated that surgical experience was an important factor affecting such decisions since all conversions occurred during the first year of training (1). In our study, operative time was comparable; due to the simplicity of the cases and the experience of the surgeons, only one case required conversion due to extensive intra-abdominal adhesions. For postoperative complications, a major complication reported by Fazili et al. was perforation of the cecum caused by excessive use of electrocautery in the vicinity of the ceco-appendicular junction (21). Other reported complications include a port abscess in a patient with a ruptured appendix, wound infections and intraperitoneal abscesses (1,21). In comparison, the complications we encountered were minor and included postoperative fever due to atelectasis and a superficial surgical site infection.

\section{Conclusion}

Laparoscopic-assisted appendectomy is a safe procedure and a feasible alternative to open appendectomy. Its benefits include shorter hospitalizations, faster postoperative recovery time, ease of learning the operative technique, and excellent cosmetic results. 


\section{Ethical Consideration}

Ethical approval from the institution's responsible ethical committee was obtained.

\section{References}

1. Zampieri N, Scirè G, Mantovani A, et al . Transumbilical laparoscopic-assisted appendectomy in children: Clinical and surgical outcomes. World J Gastrointest Endosc. 2014;6(4): 101-104.

2. Meljnikov I, Radojcić B, Grebeldinger S, et al. History of surgical treatment of appendicitis. Med Pregl. 2009;62(910):489-492.

3. Semm K. Endoscopic appendectomy. Endoscopy. 1983;15:5964.

4. Litynski GS. Highlights in the history of laparoscopy. Frankfurt: Barbara Bernert Verlag; 1996. p. 136.

5. Hartwich J, Luks FI, Watson-Smith D, et al. Non-operative treatment of acute appendicitis in children: A feasibility study. J.Pediatr. Surg. 2016;51(1):111-116.

6. Fujita T, Yanaga K. Appendectomy: negative appendectomy no longer ignored. Arch Surg 2007;142:1023-1025.

7. Hale DA, Molloy M, Pearl RH, et al. Appendectomy: a contemporary appraisal. Ann Surg 1997;225:252-61.

8. Wysocki AP, Allen J, Rey-Conde, et al. Acute appendicitis mortality. ANZ J Surg 2015;85:521-524

9. Malatani TS, Latif AA, Al-Saigh A, et al. Surgical audit: a prospective study of the morbidity and mortality of acute appendicitis. Ann Saudi Med 1991;11:209-12.

10. Kazarian KK, Roeder WJ, Mersheimer WL. Decreasing mortality and increasing morbidity from acute appendicitis. Am J Surg 1970; 119:681-5.

11. Eberts EM, McKim LH. Appendicitis: high mortality in perforated cases. Can Assoc J 1921;11:443-4.

12. Boomer LA, Cooper JN, Deans KJ, et al. Does delay in appendectomy affect surgical site infection in children with appendicitis? J Pediatr Surg 2014;49:1026-9.

13. Narsule CK, Kahle EJ, Kim DS, et al. Effect of delay in presentation on rate of perforation in children with appendicitis. Am J Emerg Med. 2010;29:890-3.

14. Meeks DW, Kao LS. Controversies in appendicitis. Surg Infect. 2008;9:553-8.
15. Bickell NA, Aufses Jr AH, Rojas M, et al. How time affects the risk of rupture in appendicitis. J Am Coll Surg. 2006;202:4016.

16. Stephens PL, Mazzucco JJ. Comparison of ultrasound and the Alvarado score for the diagnosis of acute appendicitis. Conn Med. 1999;63:137-140.

17. Brennan GD. Pediatric appendicitis: pathophysiology and appropriate use of diagnostic imaging. CJEM. 2006;8:425432.

18. Graham JM, Pokorny WJ, Harberg FJ. Acute appendicitis in preschool age children. Am J Surg. 1980;139:247-250.

19. Nicholson T, Tiruchelvam V. Comparison of laparoscopicassisted appendectomy with intracorporal laparoscopic appendectomy and open appendectomy. JSLS. 2001;5(1):4751.

20. Valla JS, Limonne B, Valla V, et al. Laparoscopic appendectomy in children: report of 465 cases. Surg Laparosc Endosc.1991;1:166-172.

21. Fazili FM, Al-Bouq Y, El-Hassan OM, et al. Laparoscopeassisted appendectomy in adults: the two-trocar technique. Ann Saudi Med. 2006;26(2):100-104.

22. Kagawa Y, Hata S, Shimizu J, et al. Transumbilical laparoscopic-assisted appendectomy for children and adults. Int J Colorectal Dis. 2012; 27:411-413.

23. Sesia SB, Haecker FM, Kubiak R, et al. Laparoscopy-assisted single-port appendectomy in children: is the postoperative infectious complication rate different? J Laparoendosc Adv Surg Tech A. 2010;20:867-871.

24. Stanfill AB, Matilsky DK, Kalvakuri K, et al. Transumbilical laparoscopically assisted appendectomy: an alternative minimally invasive technique in pediatric patients. J Laparoendosc Adv Surg Tech A. 2010;20:873-876.

25. Koontz CS, Smith LA, Burkholder HC, et al. Video-assisted transumbilical appendectomy in children. J Pediatr Surg. 2006; 41:710-712.

26. Visnjic S. Transumbilical laparoscopically assisted appendectomy in children. Surgical endoscopy. 2008;22(7):1667-71.

27. Antonacci N, Ricci C, Taffurelli G, Monari F, Del Governatore M, Caira A, Leone A, Cervellera M, Minni F, Cola B. Laparoscopic appendectomy: Which factors are predictors of conversion? A high-volume prospective cohort study. International Journal of Surgery. 2015;21:103-7. 